oxygen in place of ordinary oxygen, and the distribution of the heavy atoms among the products of reactions will indicate the part played by water in them. The striking difference in chemical properties between heavy hydrogen and ordinary hydrogen is due very largely to the differences in zero-point energy, which Prof. Polanyi calls permanent energy, the existence of which is predicted by the new quantum theory. It is possible to calculate this energy, and the results of the calculations may be checked by measurements of equilibria in which the two sorts of hydrogen participate. These experiments are in agreement with the theory. Exchange of heavy hydrogen from heavy water may occur with other compounds, such as benzene, and the mechanism of hydrogenation in ordinary reactions can also be followed in such experiments. The use of nitrogen and carbon isotopes is likely to prove important in the future.

\section{Future of the Sulphur Industry}

A PaPer by M. P. Applebey, published in Chemistry and Industry of December 28, on recent developments in the chemistry of sulphur, foreshadows important advances and perhaps far-reaching changes in those industries which are concerned with sulphur and its oxide. Researches extending over some years in the laboratories of Imperial Chemical Industries, Ltd., at Billingham have solved the problem of concentrating sulphur dioxide from metallurgical gases containing from three to seven per cent, by the ingenious method of using a sulphite-bisulphite system which can be regulated to have a moderately high $p \mathrm{H}$ in the cold and a much lower one when hot by the addition of a substance such as aluminium chloride, the hydrolysis of which is much increased by rise of temperature. It has been further discovered how to reduce the practically pure sulphur dioxide so obtained by coke:

$$
\mathrm{SO}_{2}+\mathrm{C}=\mathrm{CO}_{2}+\mathrm{S} .
$$

The reduction takes place very rapidly and almost completely at $1100^{\circ} \mathrm{C}$. and is exothermic. It is considered possible to convert economically the sulphur dioxide in dilute furnace gas on the large scale into sulphur, and since this can be transported at about a tenth of the cost of sulphur dioxide and a fifth of the cost of sulphuric acid, the process may be expected to alter radically the economic aspect of sulphur dioxide disposal.

The metallurgical industries are at present forced to make sulphuric acid to get rid of the sulphur dioxide they produce, and the disposal of this acid locally causes great difficulty, and limits the size of the smelting plants. All these troubles will largely disappear if sulphur is produced instead at one centre. Dr. Applebey visualises a new rationalisation of the metallurgical industries based on pyrites which will enable the sulphur, the non-ferrous metals and the iron to be separated at or near the port of arrival. With the new process, the manufacture of sulphur from anhydrite or gypsum becomes practicable, and lastly, the process reopens in a much more favourable manner the perennial question of the possibility of recovering the sulphur from coal. The discoveries outlined are probably the most important which have been made in the heavy chemical industries for some considerable time.

\section{The Christmas Day Empire Broadcast}

Fon the third year in succession, the British broadcasting programmes on Christmas Day included a special hour during which greetings were exchanged with various parts of the world. This year the major portion of the programme came from the countries of the Empire; the Dominions, India and Southern Rhodesia each contributed one or more scenes representing different phases of their national lives. Twenty-five different scenes were presented, and the programme was notable for the accuracy of the timing and the rapidity with which the various connexions were made in succession. It was not a steady tour round the world as was the case on a former occasion; rather had it the air of a random selection of individuals in such places as Australia, Ireland, South Africa, Canada and so on. A broad outline of the technical arrangements by which the programme was carried out was given in the issue of World Radio of December 21. In order that so many different programme sources may be blended together to form a homogeneous whole, rapid and silent switching arrangements must be provided by means of which each item may be faded into the next without a break. This is made possible by the dramatic control panel, which was originally designed by the B.B.C. to provide silent and speedy switching between a number of studios in a production of a radio play. It is a simple step to adapt the use of such a panel to the switching of long distance telephone circuits, whether these be land-line or radio.

For the purpose of the Christmas Day programme, control of fifteen channels was required, and for this purpose a recently developed dramatic control panel was brought into action at Broadcasting House. The panel is so long that it has been necessary to provide a sliding seat for the producer to keep all the controls within reach. The collection of the individual items of the programme was made along circuits connecting Broadcasting House with the Post Office International Telephone Exchange at Faraday Buildings. This exchange is connected with the radio telephone transmitting and receiving stations at Rugby and Baldock respectively, which daily handle the normal commercial radio-telephone traffic with all parts of the world. The whole programme as thus assembled at Broadcasting House was radiated through all the B.B.C. transmitting stations, including three Empire shortwave stations, while various relays were made over the local networks in different portions of the Empire. This broadcast provided simultaneously a tribute both to the very high standard of modern communication technique, and to the excellence of the organisation and international co-operation which are so necessary for its success. 